\title{
Determinants of Weight Changes During the First 96 Hours of Life in Full-Term Newborns
}

\author{
Maria João Fonseca, BScNutr, Milton Severo, PhD, Henrique Barros, MD, PhD, \\ and Ana Cristina Santos, MPH, PhD
}

\begin{abstract}
Background: Newborn weight loss (NWL) in the first 3 days of life is around 6 percent of birthweight $(B W)$. We aim to describe the determinants of an excessive and insufficient NWL in the first 96 hours of life. Methods: A sample of 1,288 full-term singletons without congenital abnormality belonging to Generation XXI birth cohort was selected. Newborns were recruited in 2005-2006 at all public units providing obstetrical and neonatal care in Porto, Portugal. Information was collected by face-to-face interview and additionally abstracted from clinical records. Anthropometrics were obtained by trained examiners and newborn weight change $(N W C)$ was estimated as (weight-BW)/BW $\times 100$. We categorized NWL as excessive (below 10th percentile of the sample distribution of NWC: $\leq-9.4 \%$ of $B W$ ), normal (between 10th and 90th percentiles: -9.3 to $-4.2 \%$ ) and insufficient (above 90th percentile: $\geq-4.1 \%$ ). Adjusted odds ratios $($ OR) and 95 percent confidence intervals (CI) were calculated using multinomial regression models. Results: Excessive NWL was positively associated with maternal age $\geq 40$ years $(O R=3.32,95 \% C I$ 1.19-9.25), maternal education $(O R=1.04,95 \%$ CI 1.00-1.09), cesarean delivery $(O R=2.42,95 \% C I 1.12-5.23)$, and phototherapy-treated jaundice $(O R=1.69,95 \% C I$ 1.00-2.87). Insufficient NWL was positively associated with low $B W(O R=2.68,95 \% C I$ 1.13-6.33), and formula/mixed feeding $(O R=1.74,95 \%$ CI 1.13-2.66). Conclusion: Excessive NWL was positively associated with maternal age and education, cesarean delivery, and phototherapy-treated jaundice. Insufficient NWL reflected child's feeding. As breastfed newborns did not lose weight excessively, but newborns with formula/mixed feeding had insufficient NWL, our study supports that breastfeeding provides excellent nutrition during this period. (BIRTH 41:2 June 2014)
\end{abstract}

Key words: birthweight, cesarean delivery, jaundice, newborn weight loss, phototherapy

Newborn weight loss (NWL) was described to range from 5.7 percent to 6.6 percent of birthweight (BW) in healthy, full-term, and exclusive breastfed newborns. The second and third days of life are those of maximum NWL (nadir) (1).

The cutoff of excessive NWL is controversial, but most studies used a total loss of $\geq 10$ percent of BW or $\mathrm{a} \geq 5$ percent loss in any 24 -hour period $(1,2)$. Exces- sive NWL has been associated with hypernatraemic dehydration, which can cause serious medical complications and even death (3-6). On the other hand, insufficient NWL, including weight gain or maintenance, has also been associated with increased risk of adverse outcomes in preterm or low BW newborns, namely over hydration and related outcomes (7-11). Newborn weight change (NWC) may also have consequences
Maria João Fonseca is a nutritionist and a Public Health PhD student, Institute of Public Health, University of Porto, Porto, Portugal. Milton Severo is a statistician, has a PhD in Public Health and is a researcher, Henrique Barros is the Director and the head, and Ana Cristina Santos is a postdoctoral researcher at the Institute of Public Health, University of Porto, and in the Department of Clinical Epidemiology, Predictive Medicine and Public Health, University of Porto Medical School, Porto, Portugal.
Address correspondence to Maria João Fonseca, Institute of Public Health - University of Porto, Rua das Taipas $n^{\circ} 135$, 4050-600 Porto, Portugal.

Accepted December 19, 2013

(C) 2014 Wiley Periodicals, Inc. 
later in life (12), as newborns must adapt their energy intake and expenditure to external conditions, programing appetite, and energy metabolism.

Despite the significant risks related to extreme NWCs, little information is available on its determinants. Martens et al showed that higher BW, female gender, epidural use, and longer hospital stay increased NWL, and greater gestational age and exclusive formula feeding decreased it (13). Regnault et al demonstrated that higher BW, gestational diabetes, and cesarean delivery increased NWL, and higher gestational age decreased it (14). Dewey et al concluded that excessive NWL was associated with primiparity, long duration of labor, use of labor medications, infant status at birth, and delayed onset of lactation (15). To the best of our knowledge, to date, no study examined the determinants of both of the extreme categories of NWC.

We aimed to describe the determinants of excessive and insufficient NWL in the first 96 hours of life.

\section{Methods}

This study involves 1,948 newborns recruited between November 2005 and August 2006 as part of Generation XXI birth cohort (16). Participants were selected at the five public hospitals providing obstetrical and neonatal care in the metropolitan area of Porto, Portugal, and all maternity units corresponded to level III, with differentiated perinatal support.

Information was collected during a face-to-face interview, conducted 24-72 hours after delivery, by trained interviewers using a structured questionnaire. Mothers were asked about their own BW, and if they did not know, were asked to indicate a category $(<2,500 \mathrm{~g}$, $2,500-4,000 \mathrm{~g},>4,000 \mathrm{~g}$ ), then the two BW variables were combined into the aforementioned categories. Mothers were classified as "primipara" if the index delivery was the first and otherwise as "multipara." Smoking habits and alcoholic beverage intake were considered throughout pregnancy, and during the third trimester.

Prepregnancy body mass index (BMI) was calculated based on the height and weight before pregnancy $\left[\mathrm{BMI}=\frac{\operatorname{wight}(\mathrm{kg})}{\operatorname{height}(\mathrm{m}) 2}\right]$. Height was measured without shoes, to the nearest $0.1 \mathrm{~cm}$. When measurement was not possible, height was reported by the mother. Prepregnancy usual weight was obtained through recall to the nearest $0.1 \mathrm{~kg}$, and if the mother did not know, we considered the reported weight at first medical visit if it occurred during the first trimester. BMI was categorized as underweight $\left(<18.5 \mathrm{~kg} / \mathrm{m}^{2}\right)$, normal (18.5$\left.24.9 \mathrm{~kg} / \mathrm{m}^{2}\right)$, overweight $\left(25.0-29.9 \mathrm{~kg} / \mathrm{m}^{2}\right)$, or obese $\left(\geq 30 \mathrm{~kg} / \mathrm{m}^{2}\right)$ (17). Weight gain was calculated based on the difference between reported weight at the end of the pregnancy and weight before pregnancy.

Data on pregnancy, gestational age, delivery characteristics, date of birth, weight, length, and head circumference at birth, need of resuscitation, Apgar scores, admission to neonatal intensive care unit (NICU), and jaundice were abstracted from medical records. Gestational age was considered as calculated by ultrasound and, only if missing, calculated using the date of last menstrual period. BW was classified in three categories: low $(<2,500 \mathrm{~g})$, normal $(2,500-4,000 \mathrm{~g})$, and high $(>4,000 \mathrm{~g})$. The Apgar score was classified as $<7$ and $\geq 7$ (18). A newborn exclusively fed with breastmilk was considered to be in the breastfed category; otherwise, the newborn was considered to be in the formula/ mixed feeding group.

During the hospital stay, trained interviewers performed one weight measurement (to the nearest $1 \mathrm{~g}$ ) for each newborn, and registered the date and time of measurement.

Of the 1,948 newborns, we excluded twins $(n=39)$, preterms (gestational age $<37$ weeks; $n=85$ ), and newborns with congenital anomaly $(n=18)$. Of the remaining 1,806 newborns, 465 had missing information on the time of measurement and six had incongruent values. We excluded 28 newborns measured after 96 hours of life and 19 outliers (1st/3rd quartile \pm 3 times the interquartile range). The final sample comprised 1,288 newborns. Differences between participants $(n=1,288)$ and eligible nonparticipants $(n=518)$, with respect to all maternal, pregnancy, delivery, and newborn characteristics, were tested and the main characteristics, are presented in Table 1. Only differences with respect to parity and type of delivery were observed, but the magnitude of those differences was not considered clinically relevant (19).

The study protocol was approved by the Ethics Committee of Hospital de S. João and by the National Commission for Data Protection. Written informed consent was obtained from all participants at recruitment.

\section{Statistical Analysis}

Longitudinal models were tested to ascertain the best approach to calculate NWC. First, we used the observed values in the formula: $\mathrm{NWC}(\%)=\frac{\text { weight-BW }}{\mathrm{BW}} \times 100$. However, weight depends on time of measurement, that is, the newborn's age when the measurement was taken. Consequently, we tested mixed-effect models adjusted for the time of measurement in hours $(t)$, in which we combined fixed coefficients up to the third degree and with the introduction of random effects on the intercept and slope. We compared four models: linear (weight $(t) \sim$ 
$\beta_{0}+\beta_{1} \times t+b_{0 i}$, quadratic (weight $(t) \sim \beta_{0}+\beta_{1} \times t+$ $\beta_{2} \times t^{2}+b_{0 i}$ ), and cubic (weight $(t) \sim \beta_{0}+\beta_{1} \times t+\beta_{2}$ $\left.\times t^{2}+\beta_{3} \times t^{3}+b_{0 i}\right)$ with only a random intercept and the same cubic model, but with random intercept and slope (weight $(t) \sim \beta_{0}+\beta_{1} \times t+\beta_{2} \times t^{2}+\beta_{3} \times t^{3}+b_{0 i}$ $\left.+b_{1 i} \times t\right)$. The chosen model was the latter, because it had the lowest Akaike Information Criterion (AIC) and Bayesian Information Criterion (BIC). To calculate $t$ (nadir), we used $($ weight $(t)) \prime=0(=) t=$ $\frac{-2 \times \beta_{2} \pm \sqrt{\left(2 \times \beta_{1}\right)^{2}-4 \times\left(3 \times \beta_{3}\right) \times \beta_{1}}}{2 \times\left(3 \times \beta_{3}\right)}(=) t=52.3$.

After establishing the adjusted NWC, to define the extreme categories of NWC, we used three different approaches in sensitivity analyses: the $\geq 10$ percent loss of $\mathrm{BW}$ and no weight loss, the 5th $(\leq-10.3 \%)$ and 95th $(\geq-3.1 \%)$ percentiles of NWC, and the 10th $(\leq-9.4 \%)$ and 90th $(\geq-4.1 \%)$ percentiles, respectively, and chose the last one.

Table 1. Maternal, Pregnancy, Delivery, and Newborn Characteristics of Participants and Eligible Nonparticipants

\begin{tabular}{|c|c|c|c|}
\hline Characteristics & $\begin{array}{c}\text { Nonparticipants } \mathrm{n}=518 \\
\text { No. }(\%)\end{array}$ & $\begin{array}{c}\text { Participants } \mathrm{n}=1,288 \\
\text { No. }(\%)\end{array}$ & $\mathrm{p}$ \\
\hline \multicolumn{4}{|l|}{ Maternal characteristics } \\
\hline \multicolumn{4}{|l|}{ Education (years) } \\
\hline$\leq 4$ & $22(4.3)$ & $92(7.2)$ & 0.126 \\
\hline $5-9$ & $200(38.8)$ & 497 (38.9) & \\
\hline $10-12$ & $153(29.7)$ & $371(29.0)$ & \\
\hline$>12$ & $140(27.2)$ & 319 (24.9) & \\
\hline Continuous variable [mean (SD)] & $11.1(4.08)$ & $10.7(4.20)$ & 0.067 \\
\hline \multicolumn{4}{|l|}{ Age at delivery (years) } \\
\hline $13-17$ & $6(1.2)$ & $21(1.6)$ & \\
\hline $18-29$ & $257(49.7)$ & $657(51.1)$ & 0.633 \\
\hline $30-34$ & $167(32.3)$ & $408(31.8)$ & \\
\hline $35-39$ & $69(13.3)$ & $169(13.2)$ & \\
\hline$\geq 40$ & $18(3.5)$ & $30(2.3)$ & \\
\hline Continuous variable [mean (SD)] & $28.8(5.88)$ & $28.8(5.63)$ & 0.923 \\
\hline \multicolumn{4}{|l|}{ Parity } \\
\hline Multiparous & 199 (38.4) & $563(43.7)$ & \\
\hline Primiparous & $319(61.6)$ & $725(56.3)$ & 0.039 \\
\hline \multicolumn{4}{|l|}{ Pregnancy characteristics } \\
\hline Tobacco smoke during third trimester & 75 (14.9) & $179(14.2)$ & 0.736 \\
\hline Presence of gestational diabetes & $18(3.5)$ & $44(3.5)$ & 0.973 \\
\hline \multicolumn{4}{|l|}{ Delivery characteristics } \\
\hline \multicolumn{4}{|l|}{ Type } \\
\hline Vaginal & $335(65.0)$ & $906(70.8)$ & \\
\hline Cesarean delivery & $180(35.0)$ & $374(29.2)$ & $0.017^{*}$ \\
\hline \multicolumn{4}{|l|}{ Newborn characteristics } \\
\hline \multicolumn{4}{|l|}{ Gender } \\
\hline Male & $259(50.0)$ & $655(50.9)$ & \\
\hline Female & $259(50.0)$ & $633(49.1)$ & 0.743 \\
\hline \multicolumn{4}{|l|}{ Birthweight (g) } \\
\hline$<2,500$ & $11(2.1)$ & $49(3.8)$ & \\
\hline $2,500-4,000$ & $482(93.1)$ & $1,192(92.5)$ & 0.109 \\
\hline$>4,000$ & $25(4.8)$ & $47(3.6)$ & \\
\hline Phototherapy-treated jaundice & $55(10.7)$ & $142(11.1)$ & 0.799 \\
\hline \multicolumn{4}{|l|}{ Feeding in maternity } \\
\hline Breastmilk & $250(48.7)$ & $617(48.9)$ & \\
\hline Formula or mixed & $263(51.3)$ & $645(51.1)$ & 0.952 \\
\hline
\end{tabular}

*High magnitude of the differences (19). 
Proportions were compared using the chi-square or Fisher exact tests as appropriate. Means and standard deviations (SD) were calculated and compared using ANOVA. Odds ratio (OR) and its 95 percent confidence interval $(\mathrm{CI})$ were computed using multinomial logistic regression models, adjusted for all relevant variables, where the outcome variable was the adjusted NWC in three categories (excessive, normal, and insufficient NWL).

Analyses were performed using SPSS (version 18.0, SPSS Inc., Chicago, Illinois, USA) and R computer (version 2.14.1, R Foundation for Statistical Computing, Vienna, Austria).

\section{Results}

The measurement time varied from 6.3 to 96.0 hours of life, mean of 45.3 (SD 19.4) hours. We compared NWC and all its potential determinants according to the time of measurement: 215 (16.7\%) measured in the first 24 hours of life, $566(43.9 \%)$ at $24-48$ hours, 388 $(30.1 \%)$ at $48-72$ hours, and $119(9.2 \%)$ at $72-96$ hours of life. Differences with respect to the main characteristics are shown in Table 2. Significant differences were observed in mother's age at delivery, type of birth, child's feeding, ICU admission, and NWC. Given these differences, we estimated NWC independently of measurement time: weight $(t) \sim 3241.442+(-9.378) \times 52.3$ $+0.119 \times 52.32+0.000 \times 52.33+b_{0 i} b_{1 i} \times 52.3$. Mean NWL was 6.7 percent (SD 2.32), the maximum loss was 18.2 percent, and the maximum gain was 5.3 percent of BW. Excessive NWL occurred in 130 (10.1\%) newborns, normal NWL in 1,029 (79.9\%), and insufficient NWL in 129 (10.0\%).

The potential NWC determinants studied were: maternal characteristics (birthweight, education, marital status, family income, age at delivery, parity, smoking habits, prepregnancy BMI, and intake of vitamins and minerals supplements before pregnancy), pregnancy characteristics (smoking, alcohol drinking, coffee intake during pregnancy and during the 3rd trimester, gestational diabetes, and weight gain), delivery characteristics (type and use of anesthesia) newborn characteristics (gestational age, gender, weight, length and head circumference at birth, need of resuscitation, Apgar score at 1 st minute, phototherapy-treated jaundice, and feeding in maternity). In the crude analysis, excessive NWL was positively associated with maternal age $(\mathrm{OR}=3.06,95 \%$ CI $1.24-7.56, \geq 40$ vs $18-29$ years old) and education (OR $=1.05,95 \%$ CI 1.01-1.10, for each year increase), cesarean delivery $(\mathrm{OR}=1.50$, 95\% CI 1.02-2.19), and phototherapy-treated jaundice $(\mathrm{OR}=1.65,95 \%$ CI 1.00-2.71), and negatively associated with length at birth $(\mathrm{OR}=0.91,95 \%$ CI 0.84
1.00). Insufficient NWL was positively associated with low $\mathrm{BW}(\mathrm{OR}=2.32$, 95\% CI 1.08-4.99, vs normal $\mathrm{BW})$ and formula/mixed feeding $(\mathrm{OR}=1.63,95 \% \mathrm{CI}$ 1.11-2.39, vs breastfeeding). All of the other potential determinants were not associated with NWC.

Table 3 presents the adjusted associations between NWC and potential determinants. Potential interactions were tested and one was observed between type of delivery and gestational age; thus, in the final model the interaction term was added (model 2). In addition, a stratified analysis was performed by time of measurement and by type of delivery, and the associations remained the same. We also performed the analysis excluding the newborns admitted to NICU, and the significance and direction of the associations remained the same. In the final model, excessive NWL was positively associated with maternal education $(\mathrm{OR}=1.04$, 95\% CI 1.00-1.09, for each year increase) and age $\geq 40$ $(\mathrm{OR}=3.32$, 95\% CI $1.19-9.25$ vs $18-29$ years old $)$, with being born by cesarean delivery ( $\mathrm{OR}=2.42,95 \%$ CI 1.12-5.23 vs vaginal delivery), and with being treated for jaundice with phototherapy (OR $=1.69,95 \%$ CI 1.00-2.87). Insufficient NWL was positively associated with maternal age between 30 and $34(\mathrm{OR}=0.60$, 95\% CI $0.36-0.99$ vs $18-29$ years old), low BW $(\mathrm{OR}=2.68,95 \%$ CI 1.13-6.33 vs normal $\mathrm{BW})$, and formula/mixed feeding $(\mathrm{OR}=1.74,95 \%$ CI $1.13-2.66$ vs breastfeeding).

\section{Discussion}

In term newborns, a physiological NWL is expected, mainly representing redistribution of fluids, as a consequence of cardiopulmonary adaptation $(20,21)$. However, in some newborns, it may also involve fat loss ascribable to the catabolic state, as in the case of small for gestational age, or ascribable to the delayed initiation of breastfeeding. Nevertheless, there are still conflicting data regarding the nature of NWL and alterations in body composition in the first week of life $(1,20,22)$. A systematic review, including 11 studies performed in healthy term newborns, established a mean NWL ranging from 5.7 to 6.6 percent of BW and the nadir of NWL in these studies was achieved around the second/third days after birth (1). This is in accordance with our results, as a mean NWL of 6.7 percent of BW, achieved at 52.3 hours of life, was observed. In our sample, 6.1 percent of the newborns lost more than 10 percent of BW (data not shown). This proportion was relatively lower than in other studies: in an Italian study, it was 7.7 percent among term breastfed newborns and, in a Californian report, 12 percent among single-term newborns $(15,23)$. In the latter, 5 percent of the newborns gained weight between birth and day 3, very different from 
Table 2. Differences with Respect to Maternal, Pregnancy, Delivery, and Newborn Characteristics, According to the Time of Measurement

\begin{tabular}{|c|c|c|c|c|c|}
\hline \multirow[b]{2}{*}{ Maternal characteristics } & \multicolumn{4}{|c|}{ Time of measurement (hours) } & \multirow[b]{2}{*}{$\mathrm{p}$} \\
\hline & $\begin{array}{c}<24.0 \\
\text { No. }(\%)\end{array}$ & $\begin{array}{c}24.0-48.0 \\
\text { No. }(\%)\end{array}$ & $\begin{array}{c}48.0-72.0 \\
\text { No. }(\%)\end{array}$ & $\begin{array}{c}72.0-96.0 \\
\text { No. }(\%)\end{array}$ & \\
\hline \multicolumn{6}{|l|}{ Maternal characteristics } \\
\hline \multicolumn{6}{|l|}{ Education (years) } \\
\hline$\leq 4$ & $13(6.1)$ & $40(7.1)$ & $34(8.8)$ & $5(4.2)$ & 0.599 \\
\hline $5-9$ & $82(38.5)$ & $215(38.2)$ & $150(39.0)$ & $50(42.4)$ & \\
\hline $10-12$ & $60(28.2)$ & $170(30.2)$ & $113(29.4)$ & $28(23.7)$ & \\
\hline$>12$ & $58(27.2)$ & $138(24.5)$ & $88(22.9)$ & $35(29.7)$ & \\
\hline Continuous variable [mean (SD)] & $10.8(4.15)$ & $10.7(4.20)$ & $10.4(4.20)$ & $11.1(4.28)$ & 0.440 \\
\hline \multicolumn{6}{|l|}{ Age at delivery (years) } \\
\hline $13-17$ & $4(1.9)$ & $10(1.8)$ & $7(1.8)$ & $0(0.0)$ & \\
\hline $18-29$ & $123(57.2)$ & $286(50.7)$ & $200(51.7)$ & $48(40.3)$ & 0.001 \\
\hline $30-34$ & $69(32.1)$ & $186(33.0)$ & $116(30.0)$ & $37(31.1)$ & \\
\hline $35-39$ & $18(8.4)$ & $68(12.1)$ & $57(14.7)$ & $26(21.8)$ & \\
\hline$\geq 40$ & $1(0.5)$ & $14(2.5)$ & $7(1.8)$ & $8(6.7)$ & \\
\hline Continuous variable [mean (SD)] & $28.1(5.08)$ & $28.7(5.60)$ & $28.7(5.71)$ & $30.7(6.08)$ & 0.001 \\
\hline \multicolumn{6}{|l|}{ Parity } \\
\hline Multiparous & $99(46.0)$ & $246(43.5)$ & $175(45.1)$ & $43(36.1)$ & \\
\hline Primiparous & $116(54.0)$ & $320(56.5)$ & $213(54.9)$ & $76(63.9)$ & 0.311 \\
\hline \multicolumn{6}{|l|}{ Pregnancy characteristics } \\
\hline $\begin{array}{l}\text { Tobacco smoke during } \\
\text { third trimester }\end{array}$ & $32(15.3)$ & $79(14.3)$ & $56(14.7)$ & $12(10.3)$ & 0.637 \\
\hline Presence of gestational diabetes & $6(2.8)$ & $23(4.1)$ & $10(2.6)$ & $5(4.2)$ & 0.566 \\
\hline \multicolumn{6}{|l|}{ Delivery characteristics } \\
\hline \multicolumn{6}{|l|}{ Type } \\
\hline Vaginal & $190(88.8)$ & $453(80.7)$ & $232(60.1)$ & $31(26.1)$ & \\
\hline Cesarean delivery & $24(11.2)$ & $108(19.3)$ & $154(39.9)$ & $88(73.9)$ & $<0.001$ \\
\hline \multicolumn{6}{|l|}{ Newborn characteristics } \\
\hline \multicolumn{6}{|l|}{ Gender } \\
\hline Male & $108(50.2)$ & $291(51.4)$ & $201(51.8)$ & $55(46.2)$ & \\
\hline Female & $107(49.8)$ & 275 (48.6) & $187(48.2)$ & $64(53.8)$ & 0.737 \\
\hline \multicolumn{6}{|l|}{ Birthweight (g) } \\
\hline$<2,500$ & $9(4.2)$ & $15(2.7)$ & $16(4.1)$ & $9(7.6)$ & \\
\hline $2,500-4,000$ & $200(93.0)$ & $530(93.6)$ & $360(92.8)$ & $102(85.7)$ & 0.085 \\
\hline$>4,000$ & $6(2.8)$ & $21(3.7)$ & $12(3.1)$ & $8(6.7)$ & \\
\hline Continuous variable [mean (SD)] & $3,234(418.2)$ & $3,250(412.6)$ & 3,235 (417.9) & $3,247(518.7)$ & 0.945 \\
\hline Need of resuscitation & $4(1.9)$ & $15(2.7)$ & $17(4.4)$ & $8(6.8)$ & 0.052 \\
\hline Apgar score 1 st minute $<7$ & $7(3.3)$ & $16(2.8)$ & $19(4.9)$ & $5(4.2)$ & 0.390 \\
\hline ICU admission & $0(0.0)$ & $3(0.5)$ & $2(0.5)$ & $4(3.4)$ & $0.016^{*}$ \\
\hline Phototherapy-treated jaundice & $22(10.3)$ & $61(10.9)$ & $39(10.2)$ & $20(16.9)$ & 0.206 \\
\hline \multicolumn{6}{|l|}{ Feeding in maternity } \\
\hline Breastmilk & $128(61.0)$ & $291(52.2)$ & $167(43.9)$ & $31(27.0)$ & $<0.001$ \\
\hline Formula or mixed & $82(39.0)$ & $266(47.8)$ & $213(56.1)$ & $84(73.0)$ & \\
\hline $\begin{array}{l}\text { Newborn weight change } \\
\text { [mean (SD)] }\end{array}$ & $-3.9(1.77)$ & $-6.3(2.61)$ & $-6.5(3.32)$ & $-5.3(3.75)$ & $<0.001$ \\
\hline
\end{tabular}

*Fisher exact test. 
Table 3. Odds Ratio and 95 percent Confidence Intervals from Multinomial Logistic Regression Model Showing the Association Between Excessive and Insufficient Newborn Weight Loss and Maternal, Pregnancy, Delivery, and Newborn Characteristics.

\begin{tabular}{|c|c|c|c|c|}
\hline & \multicolumn{2}{|c|}{ Excessive $N W L^{\mathrm{a}}$} & \multicolumn{2}{|c|}{ Insufficient $N W L^{\mathrm{a}}$} \\
\hline & Model 1 & Model 2 & Model 1 & Model 2 \\
\hline \multicolumn{5}{|c|}{ Maternal characteristics } \\
\hline Education (years) & $1.05(1.00-1.09)^{*}$ & $1.04(1.00-1.09)^{*}$ & $1.00(0.95-1.04)$ & $1.00(0.96-1.05)$ \\
\hline \multicolumn{5}{|c|}{ Age at delivery (years) } \\
\hline $13-17$ & - & - & $0.86(0.19-3.88)$ & $0.90(0.20-4.14)$ \\
\hline $18-29$ & $1^{\mathrm{b}}$ & $1^{\mathrm{b}}$ & $1^{\mathrm{b}}$ & $1^{\mathrm{b}}$ \\
\hline $30-34$ & $0.97(0.63-1.48)$ & $1.04(0.66-1.62)$ & $0.60(0.37-0.98)^{*}$ & $0.60(0.36-0.99) *$ \\
\hline $35-39$ & $0.94(0.51-1.73)$ & $1.01(0.52-1.96)$ & $1.69(1.01-2.81)^{*}$ & $1.68(0.97-2.91)$ \\
\hline$\geq 40$ & $2.62(1.03-6.62)^{*}$ & $3.32(1.19-9.25)^{*}$ & $1.15(0.33-4.06)$ & $1.18(0.31-4.45)$ \\
\hline \multicolumn{5}{|l|}{ Parity } \\
\hline Multiparous & & $1^{\mathrm{b}}$ & & $1^{\mathrm{b}}$ \\
\hline Primiparous & & $1.47(0.94-2.31)$ & & $0.94(0.61-1.47)$ \\
\hline \multicolumn{5}{|c|}{ Pregnancy characteristics } \\
\hline \multicolumn{5}{|l|}{ Gestational diabetes } \\
\hline No & & $1^{\mathrm{b}}$ & & $1^{\mathrm{b}}$ \\
\hline Yes & & $1.26(0.49-3.29)$ & & $1.39(0.51-3.77)$ \\
\hline \multicolumn{5}{|c|}{ Delivery characteristics } \\
\hline \multicolumn{5}{|l|}{ Type } \\
\hline Vaginal & $1^{\mathrm{b}}$ & $1^{\mathrm{b}}$ & $1^{\mathrm{b}}$ & $1^{\mathrm{b}}$ \\
\hline Caesarean & $1.45(0.94-2.24)$ & $2.42(1.12-5.23)^{*}$ & $0.75(0.47-1.19)$ & $0.57(0.24-1.38)$ \\
\hline \multicolumn{5}{|c|}{ Newborn characteristics } \\
\hline \multicolumn{5}{|c|}{ Gestational age (weeks) } \\
\hline $37-38$ & & $1^{\mathrm{b}}$ & & $1^{\mathrm{b}}$ \\
\hline $39-40$ & & $1.75(0.98-3.13)$ & & $1.37(0.82-2.29)$ \\
\hline $41-43$ & & $1.50(0.59-3.84)$ & & $0.15(0.02-1.15)$ \\
\hline \multicolumn{5}{|l|}{ Gender } \\
\hline Male & & $1^{\mathrm{b}}$ & & $1^{\mathrm{b}}$ \\
\hline Female & & $1.00(0.68-1.47)$ & & $0.73(0.49-1.08)$ \\
\hline \multicolumn{5}{|l|}{ Birth weight $(\mathrm{g})$} \\
\hline$<2500$ & $1.86(0.78-4.43)$ & $1.97(0.79-4.89)$ & $2.26(0.99-5.15)$ & $2.68(1.13-6.33)^{*}$ \\
\hline $2500-4000$ & $1^{\mathrm{b}}$ & $1^{\mathrm{b}}$ & $1^{\mathrm{b}}$ & $1^{\mathrm{b}}$ \\
\hline$>4000$ & $0.88(0.30-2.53)$ & $0.97(0.33-2.86)$ & $0.85(0.29-2.45)$ & $0.76(0.26-2.25)$ \\
\hline \multicolumn{5}{|l|}{ Need of resuscitation } \\
\hline No & & $1^{\mathrm{b}}$ & & 1 \\
\hline Yes & & $1.11(0.40-3.11)$ & & $0.76(0.22-2.60)$ \\
\hline \multicolumn{5}{|c|}{ Phototherapy treated jaundice } \\
\hline No & $1^{\mathrm{b}}$ & $1^{\mathrm{b}}$ & $1^{\mathrm{b}}$ & $1^{\mathrm{b}}$ \\
\hline Yes & $1.57(0.94-2.64)$ & $1.69(1.00-2.87)^{*}$ & $0.49(0.22-1.08)$ & $0.49(0.22-1.08)$ \\
\hline \multicolumn{5}{|l|}{ Feeding in maternity } \\
\hline Breast milk & $1^{\mathrm{b}}$ & $1^{\mathrm{b}}$ & $1^{\mathrm{b}}$ & $1^{\mathrm{b}}$ \\
\hline Formula or mixed & $0.83(0.55-1.25)$ & $0.72(0.47-1.11)$ & $1.74(1.15-2.63)^{*}$ & $1.74(1.13-2.66)^{*}$ \\
\hline
\end{tabular}

aReference category for dependent variable: Normal NWL. bReference category for explanatory variables. $* \mathrm{p}<0.05$. Model 1: Maternal education, age at delivery, type of delivery, birth weight, feeding in maternity, and jaundice with phototherapy as explanatory variables. Model 2: Variables in model 1 plus parity, gestational diabetes, gestational age, gender, need of resuscitation, and gestational age*type of delivery as explanatory variables.

*Corrections added on 28 March 2014, after first online publication: In table 3, the order of the values in categories '13-17' and '18-29'; and '<2500' and '2500-4000' have been switched. 
our proportion of 0.6 percent. Differences between populations were expected, as they can be attributed to many aspects such as BW, maternal age, or prevalence of breastfeeding, but also differences in the study design and in the estimation of NWL. This is the first study of this kind performed in Portugal, and it appears to demonstrate a higher proportion of newborns in the normal range of NWC than the aforementioned studies.

BW seems to be an extremely important determinant of NWC in the immediate neonatal period, being positively associated with NWL in two previous studies $(13,14)$, that is, the lighter the child is at birth, the lower the NWL. Our results were in agreement with these, as children born with $<2,500 \mathrm{~g}$ were 2.68 times more likely to be classified as insufficient NWL. The estimate precision is low, because few children were born with $<2,500 \mathrm{~g}(n=49)$, but even so, the association was strong. This result may reflect some catch-up growth, a phenomenon of accelerated growth when compared with the normal rate for age, after a period of growth-inhibiting conditions, and frequent in children that experience low BW (24).

Another important determinant of NWC is newborn feeding method $(13,25)$. Martens et al demonstrate a NWL of 5.5 percent in exclusively and partially breastfed newborns, and 2.4 percent in formula-fed newborns (13). Macdonal et al showed that breastfed newborns have a median NWL of 6.6 percent, whereas those who are formula-fed have a median of 3.5 percent (25). In our study, newborns fed with formula/mixed feeding were 1.74 times more likely to have insufficient NWL than breastfed newborns and, although not statistically significant, less likely of having excessive NWL $(\mathrm{OR}=0.72$, 95\% CI $0.47-1.11)$. These associations could be underestimated because of reverse causation, as often, when newborns start to lose weight excessively, one of the first approaches is to feed or to complement breastfeeding with formula. As a result of very different composition between colostrum and formula, this association was already expected, as the energy content in formula milk is higher when compared with colostrum (26). This study shows that, on one hand, breastfed newborns did not lose weight excessively, which means that breastmilk is sufficient to support the newborn's growth in the first 96 hours of life. Conversely, newborns fed with formula or mixed feeding were more likely to have insufficient NWL, which may represent an overfeeding. So, our study supports that breastmilk provides excellent nutrition during the first 96 hours of life, despite the concerns of mothers and pediatricians about colostrum. We also performed sensitivity analysis to test the effect of water intake. In our sample, only 17 (1.4\%) newborns had drunk water during the hospital stay. Of those who drank water, 17.6 percent had excessive NWL and 11.8 percent had insufficient NWL, whereas of those who did not drink water, 9.7 percent had excessive NWL and 9.9 percent had insufficient NWL, but these differences were not statistically significant. When we adjusted for water intake, the significance and the direction of the associations remained the same (data not shown).

The determinants of excessive NWL were higher maternal age and education, cesarean delivery, and phototherapy-treated jaundice. A mother aged $\geq 40$ years was 3.32 times more likely to have a newborn with excessive NWL than a mother aged 1829 years. It seems in agreement with the Regnault et al study, which demonstrated that for each 10 years of increase in mother's age, an increase in 0.46 percent of NWL in their children is observed (14). A child born by cesarean delivery was 2.42 times more likely to have excessive NWL, which is also in agreement with a previous study (14), whereas in another study (13), no association was observed with respect to the type of delivery. After birth, the newborn experiences a pulmonary adaptation that consists of replacing the fluid present in the lungs with air. This pulmonary adaptation is more difficult among children born by cesarean delivery, and this fact could explain that children born by cesarean delivery were more likely to have excessive NWL. The mechanism that allows the clearing of amniotic fluid from the fetal lungs remains partially unclear, but Starling forces and the pressure that newborns face during delivery are involved (27).

A newborn with phototherapy-treated jaundice was more likely to have excessive NWL. One can hypothesize that newborns with hyperbilirubinemia could have an aggregation of other health problems that could lead to an excessive NWL. An alternative explanation could be that these newborns are kept away from the mother for longer periods of time because of the phototherapy and this may have implications on feeding schedule. However, as NWC and phototherapy-treated jaundice were simultaneously evaluated, we cannot exclude the reverse causation, as some studies indicate that increased NWL as a result of inadequate fluid or caloric intake could lead to neonatal hyperbilirubinemia (28).

The odds of having a newborn with excessive NWL were higher among primiparous than multiparous mothers, although no statistically significant difference is observed. This finding is in accordance with Dewey et al (15) and Regnault et al (14), who reported that breastfed newborns from multiparous women had 0.81 percent less NWL than breastfed newborns from primiparous women. This association may be explained by greater difficulties in initiating feeding in primiparous women, because of lack of experience, and difficulties in detecting the newborn's demand for food or understanding of best positioning for breastfeeding $(15,29,30)$. 


\section{Strengths and Limitations}

Birthweight was recorded as standard procedure of the clinical setting and all weight measurements were performed prospectively, which preclude recall bias.

As we only considered one weight measurement for each child, and not measurements taken at regular periods, for instance every 5 hours, it is possible that we did not precisely detect the nadir. Nevertheless, the fact that a systematic review (1) found a mean NWL and a nadir similar to ours supports this methodology. Most of the previous studies measured their participants at a specific time point, equal for everyone, for instance, the third day of life. Because of a large variability in the time point when each newborn achieves the nadir (1), we believe that having newborns measured at different time points and then adjusting the weight for the newborn's age in hours is a new and appropriate approach.

To the best of our knowledge this is the first study aiming to evaluate the determinants of both excessive and insufficient NWL, in the immediate neonatal period. Some authors studied the determinants of the percentage of NWL $(13,14)$, as a continuous variable, not specifying a risk category. Furthermore, some of the variables had never been studied in relation to the NWC, such as mother's BW, alcoholic beverages and coffee intake, need of resuscitation, jaundice, or Apgar scores. Given the pathologies associated with these two categories of extreme NWC $(6-12,31,32)$, we think this study is a useful contribution to perinatal health.

\section{Conclusion}

Excessive NWL was mainly related to maternal and delivery characteristics, being positively associated with maternal education and age, cesarean delivery, and phototherapy-treated jaundice. Conversely, insufficient NWL seems to largely reflect the newborn characteristics, being positively associated with low BW and formula or mixed feeding. As breastfed newborns did not lose weight excessively, but newborns fed with formula or mixed feeding were more likely to have insufficient NWL, our study supports the finding that breastmilk provides excellent nutrition during the first 96 hours of life.

\section{Acknowledgments}

Portuguese Foundation for Science and Technology (SFRH/BD/69945/2010 and F-COMP-01-0124-FEDER01108; PTDC/SAU-ESA/105033/2008) and Calouste Gulbenkian Foundation. We also acknowledge the Generation XXI team and all the families involved.

\section{References}

1. Noel-Weiss J, Courant G, Woodend AK. Physiological weight loss in the breastfed neonate: A systematic review. Open Med 2008;2(4):e99-e110.

2. Wright CM, Parkinson KN. Postnatal weight loss in term infants: What is normal and do growth charts allow for it? Arch Dis Child Fetal Neonatal Ed 2004;89(3):F254-F257.

3. Clarke AJ, Sibert JR. Hypernatraemic dehydration and necrotizing enterocolitis. Postgrad Med J. 1985;61(711):65-66.

4. Cooper WO, Atherton HD, Kahana M, Kotagal UR. Increased incidence of severe breastfeeding malnutrition and hypernatremia in a metropolitan area. Pediatrics 1995;96(5 Pt 1):957-960.

5. Kaplan JA, Siegler RW, Schmunk GA. Fatal hypernatremic dehydration in exclusively breast-fed newborn infants due to maternal lactation failure. Am J Forensic Med Pathol 1998; 19(1):19-22.

6. van Dommelen P, van Wouwe JP, Breuning-Boers JM, et al. Reference chart for relative weight change to detect hypernatraemic dehydration. Arch Dis Child 2007;92(6):490-494.

7. Bell EF, Warburton D, Stonestreet BS, Oh W. High-volume fluid intake predisposes premature infants to necrotising enterocolitis. Lancet 1979;2(8133):90.

8. Bell EF, Warburton D, Stonestreet BS, Oh W. Effect of fluid administration on the development of symptomatic patent ductus arteriosus and congestive heart failure in premature infants. $N$ Engl J Med 1980;302(11):598-604.

9. Levene MI, Fawer CL, Lamont RF. Risk factors in the development of intraventricular haemorrhage in the preterm neonate. Arch Dis Child 1982;57(6):410-417.

10. Oh W, Poindexter BB, Perritt R, et al. Association between fluid intake and weight loss during the first ten days of life and risk of bronchopulmonary dysplasia in extremely low birth weight infants. J Pediatr 2005;147(6):786-790.

11. Wadhawan R, Oh W, Perritt R, et al. Association between early postnatal weight loss and death or BPD in small and appropriate for gestational age extremely low-birth-weight infants. $J$ Perinatol 2007;27(6):359-364.

12. Stettler N, Stallings VA, Troxel AB, et al. Weight gain in the first week of life and overweight in adulthood: A cohort study of European American subjects fed infant formula. Circulation 2005;111(15):1897-1903.

13. Martens PJ, Romphf L. Factors associated with newborn in-hospital weight loss: Comparisons by feeding method, demographics, and birthing procedures. J Hum Lact. 2007;23(3):233-241, quiz 42-5.

14. Regnault N, Botton J, Blanc L, et al. Determinants of neonatal weight loss in term-infants: Specific association with pre-pregnancy maternal body mass index and infant feeding mode. Arch Dis Child Fetal Neonatal Ed. 2011;96(3):F217-F222.

15. Dewey KG, Nommsen-Rivers LA, Heinig MJ, Cohen RJ. Risk factors for suboptimal infant breastfeeding behavior, delayed onset of lactation, and excess neonatal weight loss. Pediatrics 2003;112(3 Pt 1):607-619.

16. Larsen PS, Kamper-Jorgensen M, Adamson A, et al. Pregnancy and birth cohort resources in Europe: A large opportunity for aetiological child health research. Paediatr Perinat Epidemiol 2013;27(4):393-414.

17. Expert Panel on the Identification, Evaluation, and Treatment of Overweight in Adults. Clinical guidelines on the identification, evaluation, and treatment of overweight and obesity in adults: executive summary. Am J Clin Nutr. 1998;68(4):899-917.

18. Moster D, Lie RT, Irgens LM, et al. The association of Apgar score with subsequent death and cerebral palsy: A populationbased study in term infants. J Pediatr 2001;138(6):798-803. 
19. Husted JA, Cook RJ, Farewell VT, Gladman DD. Methods for assessing responsiveness: A critical review and recommendations. J Clin Epidemiol 2000;53(5):459-468.

20. Modi N, Betremieux P, Midgley J, Hartnoll G. Postnatal weight loss and contraction of the extracellular compartment is triggered by atrial natriuretic peptide. Early Hum Dev 2000;59(3):201-208.

21. Singhi S, Sood V, Bhakoo ON, et al. Composition of postnatal weight loss and subsequent weight gain in preterm infants. Indian J Med Res 1995;101:157-162.

22. Sulyok E. Physical water compartments: A revised concept of perinatal body water physiology. Physiol Res 2006;55(2):133-138.

23. Manganaro R, Mami C, Marrone $\mathrm{T}$, et al. Incidence of dehydration and hypernatremia in exclusively breast-fed infants. J Pediatr 2001;139(5):673-675.

24. Gafni RI, Baron J. Catch-up growth: Possible mechanisms. Pediatr Nephrol 2000;14(7):616-619.

25. Macdonald PD, Ross SR, Grant L, Young D. Neonatal weight loss in breast and formula fed infants. Arch Dis Child Fetal Neonatal Ed. 2003;88(6):F472-F476.

26. Hester SN, Hustead DS, Mackey AD, et al. Is the macronutrient intake of formula-fed infants greater than breast-fed infants in early infancy? J Nutr Metab 2012;2012:891201.
27. Lavoue V, Voguet L, Laviolle B, et al. Caesarean section at term: The relationship between neonatal respiratory morbidity and microviscosity in amniotic fluid. Eur J Obstet Gynecol Reprod Biol 2013;169(2):239-243.

28. Chang RJ, Chou HC, Chang YH, et al. Weight loss percentage prediction of subsequent neonatal hyperbilirubinemia in exclusively breastfed neonates. Pediatr Neonatol 2012;53(1): $41-44$.

29. Hilson JA, Rasmussen KM, Kjolhede CL. High prepregnant body mass index is associated with poor lactation outcomes among white, rural women independent of psychosocial and demographic correlates. J Hum Lact 2004;20(1):18-29.

30. Ben Slama F, Ayari I, Ouzini F, et al. [Exclusive breastfeeding and mixed feeding: Knowledge, attitudes and practices of primiparous mothers]. East Mediterr Health J. 2010;16(6):630-635.

31. Gorski JN, Dunn-Meynell AA, Hartman TG, Levin BE. Postnatal environment overrides genetic and prenatal factors influencing offspring obesity and insulin resistance. Am J Physiol Regul Integr Comp Physiol 2006;291(3):R768-R778.

32. Schmidt I, Fritz A, Scholch C, et al. The effect of leptin treatment on the development of obesity in overfed suckling Wistar rats. Int J Obes Relat Metab Disord 2001;25(8):1168-1174. 